\title{
Apologia of everyday life
}

\author{
Edouard Vuillard (1868-1949). The Sick Child. \\ 1892 ca. 20.5 x $26.5 \mathrm{~cm}$. Oil on canvas. Private collection.
}

This small oil painting by Vuillard is a coloured impression of a familiar scene. The child has fallen asleep and the mother on tiptoes can finally leave the room. If it were not for the title we would not suspect that the sleep which has overcome the child is a moment of calm during the course of a disease. Painted at a time when the infant mortality from childhood infections reached as high as two thirds of cases, the scene describes something much more dramatic than we can perceive today. The serenity of the mother as she removes a soiled garment seems to enter into the dreams of the child which materialise in the kaleidoscope of colours animating the semidarkness of the room, in a subdued but vivid manner.

The promising rest and respite from disease are reconciled in the awareness of being in a familiar place, of belonging to a dimension where solitude cannot add to the burden of the already difficult condition caused by the illness. But even the possibility of looking after the needs of the house, without allowing the care for the sick to upset rhythms and possibilities, is a crucial resource in terms of economic, physical and psychological sustainability on the part of caregivers, and especially so given the scale that chronic illnesses have taken on in our countries.

This day-to-day aspect of care is typical of the home setting and is rendered more appropriate than the hospital setting, which appears increasingly foreign and violent with respect to the home, regardless of the formal attempts to humanise its organisation or infrastructural features.

An objective of progressive dehospitalization of chronic illnesses, without losing the attribute of specialist excellence which only the hospital seems able to guarantee, is the right and proper step which regards not only the efficiency and inexpensiveness of the healthcare service, but the dignity itself in the way the patient is taken care of, which is interwoven with the familiarity of daily actions and relationships which would otherwise be difficult or completely impossible.

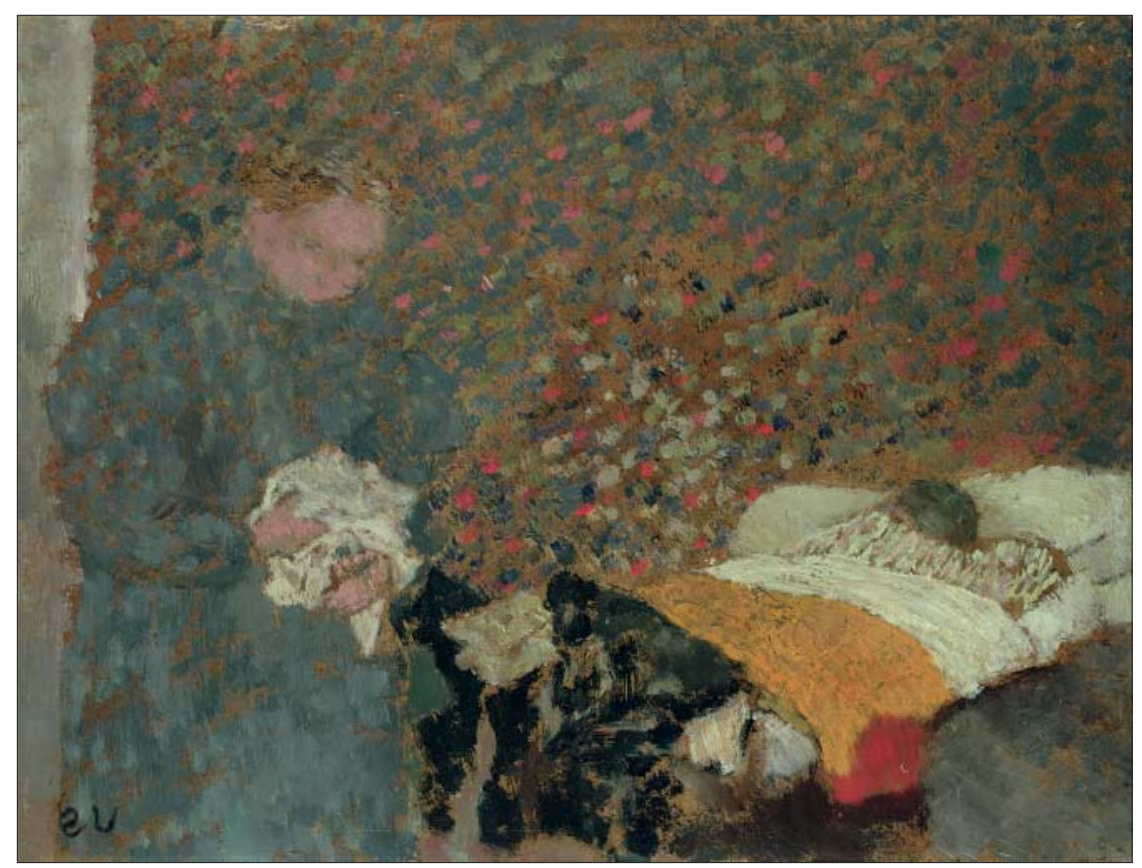

